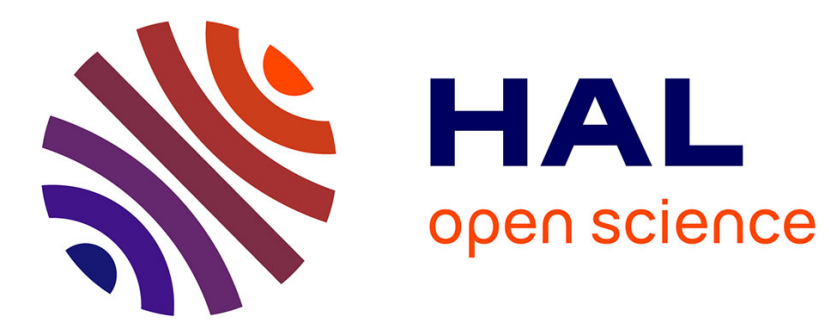

\title{
IdeS in anti-glomerular basement membrane disease: Is this the new deal?
}

\author{
Cédric Rafat, Yosu Luque
}

\section{To cite this version:}

Cédric Rafat, Yosu Luque. IdeS in anti-glomerular basement membrane disease: Is this the new deal?. Kidney International, 2019, 96, pp.1068 - 1070. 10.1016/j.kint.2019.08.017 . hal-03488559

\section{HAL Id: hal-03488559 \\ https://hal.science/hal-03488559}

Submitted on 21 Dec 2021

HAL is a multi-disciplinary open access archive for the deposit and dissemination of scientific research documents, whether they are published or not. The documents may come from teaching and research institutions in France or abroad, or from public or private research centers.
L'archive ouverte pluridisciplinaire HAL, est destinée au dépôt et à la diffusion de documents scientifiques de niveau recherche, publiés ou non, émanant des établissements d'enseignement et de recherche français ou étrangers, des laboratoires publics ou privés.

\section{다)(1) $(5$}

Distributed under a Creative Commons Attribution - NonCommercial| 4.0 International 
IdeS in anti-glomerular basement membrane disease, is this the new deal?

Sub heading : IdeS for rapid clearance of anti-GBM antibodies

\title{
Cédric RAFAT 1 , Yosu LUQUE 1,2
}

1Urgences Néphrologiques et Transplantation Rénale, Assistance Publique-Hôpitaux de Paris (AP-HP), Hôpital Tenon, F-75020 Paris, France

2 Sorbonne Université, Inserm, UMR_S1155, F-75020 Paris, France

\begin{abstract}
IdeS, a proteinase from Streptococcus pyogenes, cleaves immunoglobulin IgG antibodies with a unique specificity. Herein, the authors report the dramatic efficacy of IdeS on the levels of anti-glomerular membrane (anti-GBM) auto-antibodies in three patients with Goodpasture disease refractory to standard therapy. The levels of anti-GBM auto-antibodies were reduced to near-zero levels within two hours of the injection. However, all patients ultimately required permanent hemodialysis due to the late intervention in the course of the disease
\end{abstract}

\section{Key words : apheresis, IdeS, Goodpasture disease}

Goodpasture disease (GD) is generally regarded as a canonical form of IgG associated autoimmune disease and therefore provides a strong rationale for the application of IgG auto-antibody targeted therapies. Current therapy of GD consists of cyclophosphamide, corticosteroids and plasma exchange and has not significant advanced over the last 25 years. Therefore the "Rapid clearance of anti-GBM antibodies by IgG degrading enzyme of streptococcus pyogenes (IdeS) in three patients with refractory anti-GBM disease" a pilot study investigating the potential efficacy of IdeS should be welcomed as a novel therapeutic avenue. IdeS, a proteinase from Streptococcus pyogenes, cleaves immunoglobulin IgG antibodies with a unique degree of specificity (1) to achieve a swift, complete and specific IgG hydrolysis by digesting the immunoglobulin at a single site located in the hinge region, subsequently generating Fab' and Fc/2 fragments. Having shown promising results in a 
variety of experimental models of auto-immune diseases including immune thrombocytopenic purpura, neuromyelitis optica and Guillain-Barré disease, and experimental glomerulonephritis, IdeS emerged a potent novel therapy and a plausible contender for GD treatment (2). The efficacy of IdeS was reported in 24 out of 25 highly sensitized patients awaiting kidney transplantation who were conseuently successfully cleared for transplantation (3). Investigators were able to withhold apheresis -a mainstay in desensitization protocols- in both the Swedish and the American cohorts treated with IdeS.

This report highlights a quintessential feature of Goodpasture disease in respect to therapeutic management, namely that timing is essential. All three patients were given IdeS in refractory disease. In fact, the plasma creatinine levels upon admission (534, 837 and $2046 \mu \mathrm{mol} / \mathrm{L}$ ) may well have discouraged some practitioners to provide therapy altogether, whether standardized or experimental. Accordingly, the proportion of glomerular crescents upon histology examination ranged between $84 \%$ and $100 \%$. Yet the crux of the study lies elsewhere. The authors were able to document the dramatic efficacy of IdeS on anti-GBM IgG antibodies titers. The anti-GBM IgG plummeted to near zero levels within 2 hours of the injection, as eloquently depicted by the authors. This is per se a valuable information, especially when the efficiency of IdeS is compared to IgG removal kinetics achieved by plasma exchange (one third per session). Even immunoadsorption does not fare as well: IgG reduction reaches $80 \%$ per session and, in a cohort of 23 patients with GD, it took a mean number of 9 sessions to rein in anti GBM levels (4). The issue of timely therapeutic intervention is highly relevant to a forthcoming multicentre phase II trial: An Open-Label Phase II Study to Evaluate the Efficacy and Safety of IdeS in Anti-GBM Disease (GOOD-IDES) (NCT03157037). The main inclusion criteria for this trial is the presence of severe acute kidney injury defined by eGFR $<15 \mathrm{ml} / \mathrm{min} / 1.73 \mathrm{~m} 2$ (by MDRD equation) or an unfavourable course with standard treatment. Results will need to be scrutinized with this point kept in mind.

Another key property of IdeS resides in its transient effect on IgG levels. This key feature may be viewed as a mixed blessing. On one hand, plasma exchanges needed to be resumed within days of the IdeS injection, prompted by a significant, albeit limited anti-GBM IgG titer rebound. On the other, not only are other classes of immunoglobulin unaffected by IdeS, but 
concerns regarding excessive immunosuppression induced by protracted IgG depletion are less founded. These observations call for further remarks 1 ) In the short term, IdeS is not designed to supersede in the near future current immunosuppressive therapies and /or plasma exchange therapies 2) In fact IdeS, immunosuppressive treatments and plasma exchanges should be envisaged as complementary and potentially synergistic/adjunctive treatment. It may be posited that immunosuppressive therapy may mitigate the rebound of anti-GBM IgG and abrogate the need for repeat IdeS injection. This interpretation, if proven correct, would be a fortunate scenario given the issues surrounding the risk of immunogenicity in case of repeat injections. Reciprocally, IdeS may alleviate the cumulative immunosuppressive dosage 3) Further studies will need to determine how to strategize IdeS with the current therapeutic options and how the addition of an IgG depleting agent on top of a potentially reduced dosage of immunosuppression will equate in terms of infectious and other iatrogenic complications.

The authors also rightly acknowledge that the original heuristic whereby Goodpasture disease is chiefly auto-antibody mediated by nature has been repeatedly challenged. Multiple works have emphasized the role of T cells in the pathogenesis the disease (5), or even, more provocatively, called in question whether it is solely an autoantibody mediated process. In an avian model of glomerulonephritis, animals with impaired humorally mediated immunity due to bursectomy developed crescentic glomerulonephritis similarly to controls despite the absence of IgG glomerular deposition (6). Anecdotal observations have reported isolated respiratory clinical manifestations together with linear IgG fixation on the glomerular basement membrane albeit without renal disorder. More importantly, experimental studies have shown that the full-blown histological pattern could be replicated solely by manipulating resident renal cells genetically (7) suggesting that antibody deposition is perhaps not the sole trigger responsible for glomerular injury. At any rate, IdeS may well enable clinicians to arbitrate between these different claims. One last issue with fundamental ramifications arises from this work: the authors demonstrated that IdeS cleaved kidney bound-autoantibody in all three cases (Fc fragment was absent on staining), however Fab' staining was positive in two cases with the usual linear glomerular basement membrane deposition pattern. From an immunopathological standpoint, can we rest assured that the Fab' fragment is devoid of any pathological significance? The most recent line of 
evidence has highlighted the crucial role of intact Fcy receptor in the induction of experimental glomerulonephritis. Yet early studies suggest that Fab' fragment should not be viewed as an innocent bystander. In the setting of experimental nephrotoxic nephritis, using papain, a forerunner of IdeS as it cleaves IgG in Fab' and Fc fragments, investigators evidenced that animals nevertheless developed proteinuria, albeit transient (8). In a different experimental model, Salant et al evidenced that Fab' targeting fragments tubular antigen could in fact alter glomerular permeability by depositing in the capillary wall thereafter eliciting glomerular proteinuria (9).

In the meantime, the work of Soveri et al provides a glimpse of a novel therapy which will hopefully establish a new landmark in both in our understanding and management of Goodpasture disease.

Cédric RAFAT declares having no conflict of interest related to this paper

Yosu LUQUE declares having no conflict of interest related to this paper

1. Johansson BP, Shannon O, Björck L. IdeS: a bacterial proteolytic enzyme with therapeutic potential. PLoS ONE. 27 févr 2008;3(2):e1692.

2. Collin M, Björck L. Toward Clinical use of the IgG Specific Enzymes IdeS and EndoS against Antibody-Mediated Diseases. Methods Mol Biol. 2017;1535:339-51.

3. Jordan SC, Lorant T, Choi J, Kjellman C, Winstedt L, Bengtsson M, et al. IgG Endopeptidase in Highly Sensitized Patients Undergoing Transplantation. N Engl J Med. 03 2017;377(5):442-53.

4. Biesenbach P, Kain R, Derfler K, Perkmann T, Soleiman A, Benharkou A, et al. Longterm outcome of anti-glomerular basement membrane antibody disease treated with immunoadsorption. PLoS ONE. 2014;9(7):e103568.

5. Luque Y, Cathelin D, Vandermeersch S, Xu X, Sohier J, Placier S, et al. Glomerular common gamma chain confers $B$ - and T-cell-independent protection against glomerulonephritis. Kidney Int. 2017;91(5):1146-58. 
6. Bolton WK, Tucker FL, Sturgill BC. New avian model of experimental glomerulonephritis consistent with mediation by cellular immunity. Nonhumorally mediated glomerulonephritis in chickens. J Clin Invest. mai 1984;73(5):1263-76.

7. Ding M, Cui S, Li C, Jothy S, Haase V, Steer BM, et al. Loss of the tumor suppressor Vhlh leads to upregulation of $\mathrm{Cxcr} 4$ and rapidly progressive glomerulonephritis in mice. Nat Med. sept 2006;12(9):1081-7.

8. Unanue E. EXPERIMENTAL GLOMERULONEPHRITIS: IV. PARTICIPATION OF COMPLEMENT IN NEPHROTOXIC NEPHRITIS. Journal of Experimental Medicine. 1 juin 1964;119(6):965-82.

9. Salant DJ, Madaio MP, Adler S, Stilmant MM, Couser WG. Altered glomerular permeability induced by $F\left(a b^{\prime}\right) 2$ and Fab' antibodies to rat renal tubular epithelial antigen. Kidney International. 1 janv 1982;21(1):36-43. 